\title{
BASIS OF ARCHITECTURAL SURVEY BETWEEN GEOMETRY AND REPRESENTATION. A FIRST EDUCATIVE APPROACH
}

\author{
Eugenia Comparetto ${ }^{1}$, Martino Pavignano ${ }^{1}$, Ursula Zich ${ }^{1}$, Ornella Bucolo ${ }^{2}$, \\ \& Daniela Miron ${ }^{2}$ \\ ${ }^{I}$ Department of Architecture and Design, Politecnico di Torino (Italy) \\ ${ }^{2}$ LabRilDoc, Department of Architecture and Design, Politecnico di Torino (Italy)
}

\begin{abstract}
This paper illustrates the educative path - aimed at learning the basis of architectural survey - we propose to the students in the first year, as part of the Drawing and Survey Laboratory (bachelor's degree in Architecture). The primary focus of the Laboratory is to guide them in studying and using the graphic languages and related fundamental tools. In this case, architectural survey comes as a cognitive tool of fundamental importance for the analysis and understanding of architectural artefacts. The main objective of the exercises carried out during the Laboratory is to prepare student by a gradual theoretical and technical path for the direct and indirect operations of survey. During the first semester the course includes a first operation of surveying an architectural drawing (during the exercise of critical redraw of a published project), giving birth to an ideal scalar approach to the themes of survey, both manual (direct survey) and digital (PR, SfM), which combines and develops horizontal and vertical skills. Here, we discuss the main passages of the path of survey through an emblematic case study from Torino.
\end{abstract}

Keywords: Architectural drawing and survey, architectural education, integrated architectural survey, architectural heritage, process of knowledge.

\section{Introduction: The Architect and the study of the built environment (MP, UZ)}

Since the dawn of his profession, the Architect has been the professional who shapes the built world by designing its volumes, spaces and places. However, it is important to remember that in the contemporary world, in the European context and specifically in Italy, the Architect has to deal with a highly stratified context, characterized by the presence of a significant amount of existing building and architectural/landscape heritage, that arise the necessity of a productive dialogue (Piano \& Cassigoli 2009). Therefore, the Architect is increasingly working on existing buildings. This makes it necessary that he should be able, even if often supported by other professionals, to obtain metric, material, technological knowledge of the architectural artefacts before working on it. Then, it is necessary to provide students of Architecture with the skills and related tools that might be useful to build this knowledge.

Over the years, however, the transition from a five-year to a $3+2$ degree course (Bologna process) has certainly required a remodeling of the educational programs, with the primary purpose of preparing three-year graduates in the world of work with specific expendable skills. Among these skills, the geometric knowledge (and not only) of the built environment stands out. In the architectural field, this process takes place through that set of operations, not only technical, but theoretical, that are grouped under the name of Survey (Ippolito 2016). Thanks to new technologies, it has been recognized for years as a result of integration of multiple analysis processes (historical, material, structural, etc.) and different measurement techniques (eg. meters, disto, theodolite, LIDAR, photogrammetry and SfM, etc.).

\section{Designing the educative path (UZ)}

Observe, notice, grasp and annotate, graphically. This, in short, is a first approach to the architectural object. But how to observe, what to note, what aspects to grasp or to write down and... which is the right communicative modality? Usually, these are the questions we ask our students of the Drawing and Survey Laboratory of the first year of the bachelor's in Architecture. They are extremely heterogeneous students by school training; therefore, we cannot make use of prerequisites, we must offer them a complete educative path that, within a few months, allows them to face the subsequent courses. 
This path must aim at structuring the scientific, theoretical and applicative bases of the graphic language: the Architect's own expression, useful to conceive, know and communicate the built environment. Moreover, we need to provide the bases for the Survey, following the Ministerial rules (DM 30 October 2015, n. 855) that, for our discipline, Drawing, indicates drawing as «a means of knowledge of the laws that govern the formal structure, an instrument for the analysis of existing values, an expressive act and visual communication of the design idea at the different dimensions» and survey «as a tool for knowledge of the architectural, urban and environmental reality, through direct and instrumental methodologies up to the most advanced ones».

We face the issues of direct analysis of existing buildings by means of theoretical lectures and practical applications, starting from the foundations and applications of descriptive geometry, to consciously work on drawing and redrawing published project and survey practices. Experiencing with redrawing of published projects allows students to investigate the graphic language and formulate their first interpretations (Spallone 2016; Zich, Comparetto and Pavignano 2019). Subsequently, the educational path makes use of the newly acquired skills to approach the real object, starting from the critical reading of graphical sources and developing direct and indirect survey of the built artefact.

\section{Case study: Casa Maffei in Torino (UZ)}

Choosing the example becomes part of the educational path: we need an easily accessible building (to let students apply survey techniques), whose original project is still available. It also must be extremely significant for a reading through the rudiments of the perceptual survey, between form and proportion. For this exercise we chose Casa Maffei in Torino, sited in corso Montevecchio 50.

We start from the Census of environmental cultural heritage in the municipality of Torino which systematized in a logical grid heterogeneous information from archival and bibliographic sources: it describes Casa Maffei as a «civilian building [...] of historical, artistic and environmental value, designed by A. Vandone di Cortemiglia in an Art Nouveau style with Lombard school influences in 1904» (Nelva 1984). It is precisely from the critical reading of the archive documents that the activity begins (Figure 1).

\subsection{Maffei's house in Turin: Redrawing the project (EC-UZ)}

The redrawing activity is an opportunity to discuss the validity of the graphical sources, the relationship between the scale of representation and the qualitative/quantitative aspects of the information and graphic standards (both for its original representation and its remediation). The practice of redrawing an architecture can have multiple declinations, from working on an archive drawing or on published sources, to interpreting a photographic image or the result of its geometric transformation. As such, redrawing a building offers the possibility of exploring the different values of representation, ranging from the study of the design idea to the analysis of the as built by means of its survey. Redrawing is a heuristic practice that involves critical evaluations of the graphic sources; in fact: «redrawing consists of a real transcription, with a high content of abstraction: the process starts from the recognition of each sign, as part of the building [...] and arrives to another type of sign, which responds to the codified language of the architectural drawing. Each line of the graphic sources must therefore be read, recognized, interpreted and then retraced» (Spallone 2016, p. 735). In this sense, redrawing a project starting from a graphic source, allows students to study the architectural forms not from the real object, but from its representations, operating a survey of an architecture 'on paper'. This process gets the student used in reading drawings in various scales. Consequently, the student is obliged to think on the concept of representation scale. The information offered by the sources never seems exhaustive and often the work becomes a search for those data to be considered more reliable than others to base one's hypothesis of critical reading. Therefore, by tackling the redrawing in scale, the student is led to think on the qualitative/quantitative aspects of the graphic information to be managed: if representing at the same scale of the graphic source, he will adopt the same level of detail of the source itself, adding elements derived from the graphic conventions of architectural drawing. By making the change of scale to a less detailed one (i.e. from 1:100 to 1:50), he will decide which information is visible on this scale and which information will be lost and will remain only on the original drawings. For example, in this case, the 1:100 metric scale indicated in the drawings and the presence of some dimensions allow the student to correctly scale them on the CAAD. This step is the first one in order to redraw the original project. It follows the vectorization of the graphic source. This task allows the student to practice with the software and the notions of physical drawing scale and scaling of the same in the virtual (therefore infinite) space of the CAAD. During the process, however, it is necessary to make a reduction of the measure detected on the drawing, bringing them back to finite numbers that can be easily interpreted. This last step unites the practice of redrawing the survey practice, thus making the redrawing activity more like the restitution of a survey. The procedure is in fact to read a measure (which in this case is a 
measure on a drawing) and bring it back on the drawing itself. As a process of knowledge, all the iconographic apparatus represents a tool to study its author's graphic codes and to correctly interpret their use. First, we focus on the façade, extrapolating the measurements from the project plans, suitably scaled. In order to prepare the student for the survey of the facades through the use of the RDF software.

Figure 1. The case study: Palazzo Maffei in Turin. a) the building and its urban context; b) main façade; c), d), e), f) original project of Palazzo Maffei from the Building Archive of the City of Turin, all right reserved.

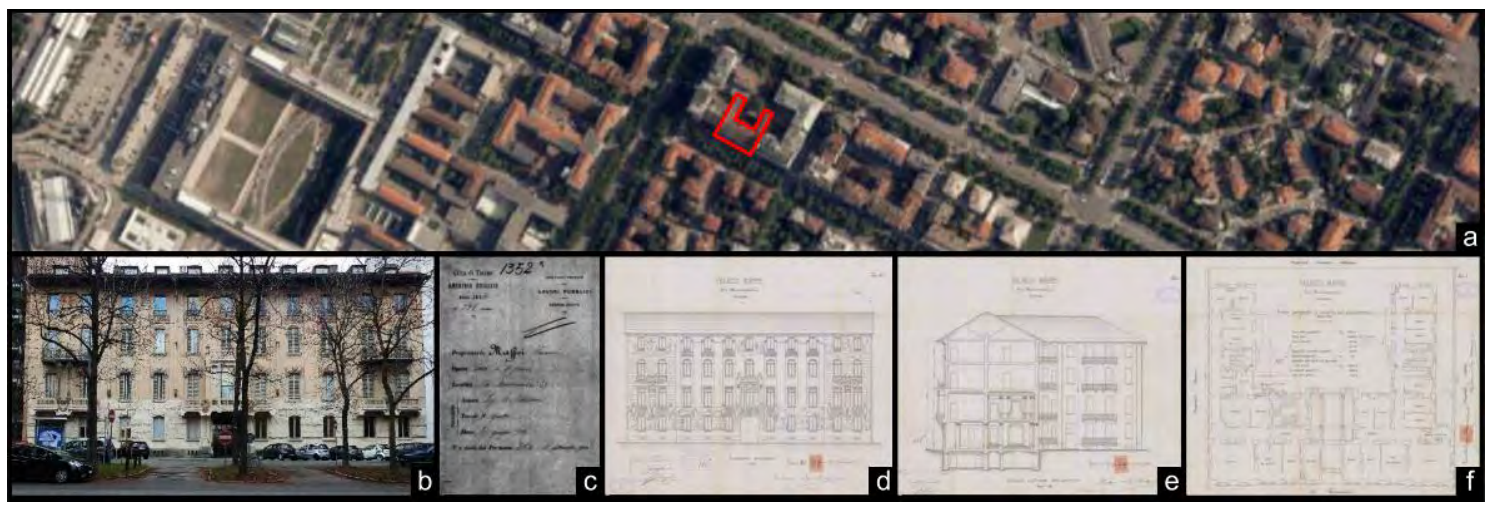

\subsection{Maffei's house in Turin: Geometrical perspective rectification (OB-DM-MP)}

As second step, we introduce simplified methodologies for indirect survey: the photo rectification (of a geometric type) is one of the most appropriate in the first year of Architecture. From the point of view of descriptive geometry, straightening is an automated application of projective homology that transforms a central perspective into an orthogonal projection (Bassi Gerbi 1995) usable for the survey and analysis of façades or flat architectural elements, characterized by evident horizontal and vertical axiality. Flat objects are those artifacts where we can recognize one or more vertical reference plans (on each elevations) on which lie a sufficient number of elements characterizing the façades to be surveyed (openings, decorations, technological elements, etc.).

The described process involves two distinct steps: the acquisition of data, in this case shooting the photos, and the graphic restitution. The latter is the set of operations designed to reconstruct the true form of the photographed object. This process requires at least a photo of the object and the knowledge of at least two significant dimensions, to be measured on the object (one vertical and one horizontal). The operative practice starts from the correct method of photo acquisition: the visual field of the optical cone must display the sectors on which the two linear measures - which will allow the scaling of the frame (both on the straightening software and on the CAAD) - lie. This technique is adaptable to the most common forms of radiometric acquisition available today, such as smartphones, tablets, compact cameras. The photo of the element to be rectified must be appropriately acquired, possibly using lenses that contain medium-radial distortions, setting a resolution (dpi) that allows enlargement, up to the reading of the detail of interest, and without excessive contrast. It is therefore clear that the distance between the object to be photographed and the point of view is a not negligible parameter.

We use RDF, a software developed at the IUAV Photogrammetry Laboratory at the end of the 90s (www.iuav.it/sistema-de/laboratori2/cosa-offri/software/index.htm), still usable on the most modern pc. The operations to be carried out to obtain a rectification must be carried out carefully and without further simplifications. We refer to the operating manual available on the IUAV site.

We summarized the procedure performed to obtain the geometric straightening of a portion of the bas-reliefs to decorate the façade of Casa Maffei. Given its location (fourth floor), this portion of the decorative apparatus cannot be directly reached, therefore it would be very complicated to acquire the two linear measures for its straightening. Consequently, as a first procedure, an overall geometric straightening of the façade was performed using two dimensions, directly acquired on the building, relating to the total width of the façade and its height, measured from the upper edge of the windowsill on the mezzanine floor to the lower edge of the band of decoration placed under the windows of the fourth floor. While operating in geometric mode, it is necessary to consider the almost total impossibility of verifying the errors committed, both in the digitization of the geometric parameters and in recognizing them directly on the façade. So students must be aware of the risk of falling into a series of errors, for example: setting erroneous parallelisms of bundles of straight lines, obtained from architectural elements on which there is no possibility of control or verification; or processing the drawing of a façade without considering the error of scale and perspective due to the assembly of elements that deviate strongly from the height of the reference plane. 


\subsection{Maffei's house in Turin: Redrawing the rectified photos (EC-UZ)}

Once obtained the rectified photos of the elevation of the house (and its details), we proceed again to the redrawing of the same on CAAD (Figure 2f). Also, in this case the student must organize the layers of the file and, therefore, practice the critical extrapolation, for quality and quantity, of the elements of the elevation. In this phase, the CAAD tool proves to be the most suitable for relating the different digitalized sources. The process of redrawing on rectified photos differs from that of the graphic source by mean of data interpretation: synthetizing the signs that characterize the form is now an operation done directly on the object photo (Figure $2 \mathrm{~h}$ ), thus not mediated by the language of the author of the archival drawing (Figure $2 \mathrm{~g}$ ).

Figure 3. Issues of redrawing and surveying Casa Maffei: a) original picture, horizontal and vertical alignments are highlighted with red lines; b) rectified photo; c) original picture used for the detail of the decoration, horizontal and vertical alignments are highlighted with red lines; d) rectified photo; e) redrawing a slice of the elevation on the archival graphic source; f) redrawing the same slice on the rectified photo; $g$ ) redrawing the detail of the decoration on the archival graphic source; $h$ ) redrawing the same detail on the rectified photo; i) SfM elaborated model (half of the façade) as oriented by the software; j) orthographic view of the same model; $k$ ), l) Detail SfM elaborated model.

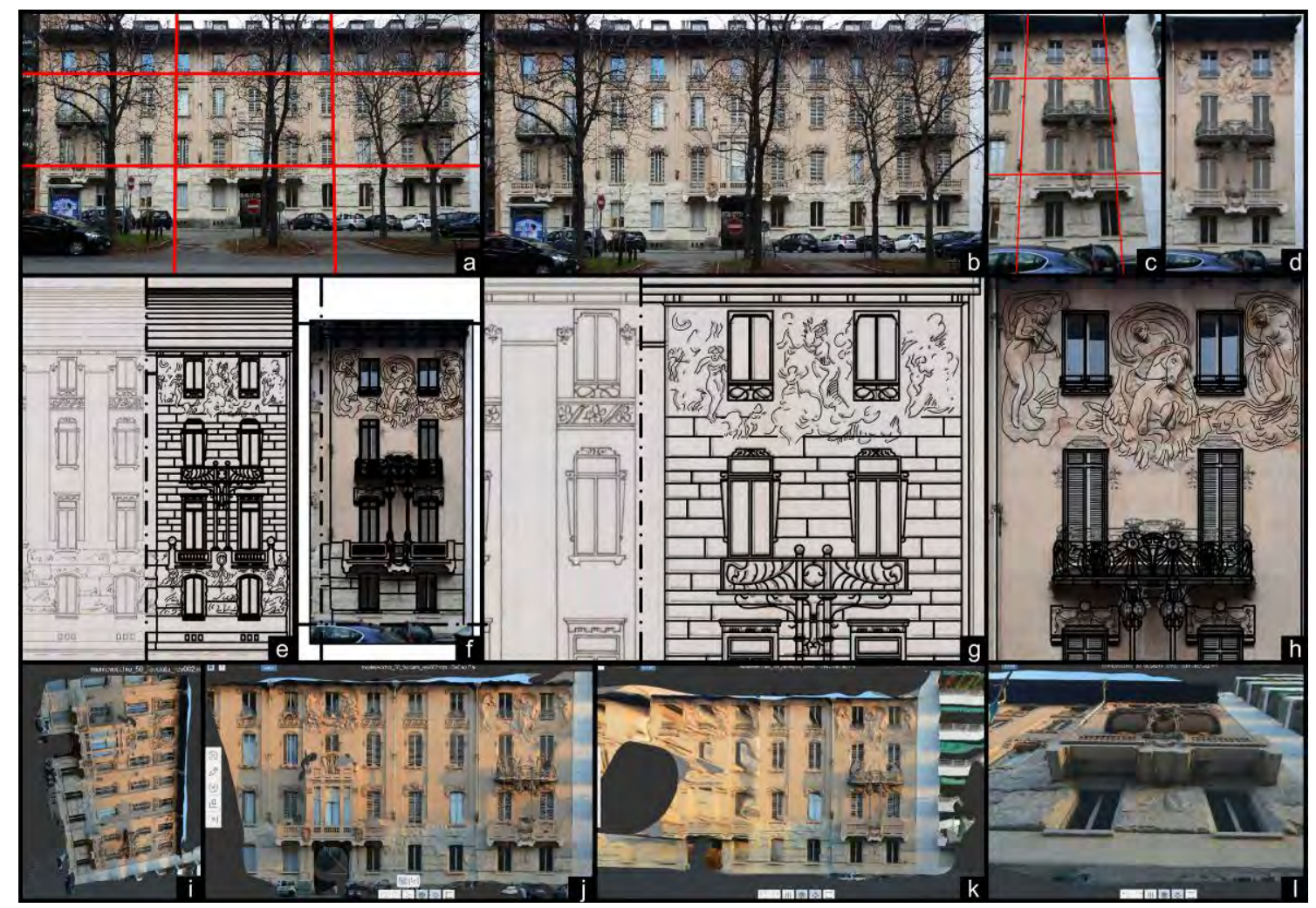

\subsection{Casa Maffei in Turin: The SfM survey (MP)}

The latest didactic experience deal with automated frame processing, with the range imaging Structure from Motion approach (Häming and Peters 2010): in this way we move from the processing of a single photo, which allows the reconstruction of a rectified photo (and consequently to extrapolate only two-dimensional measurements on the reference plane), to an elaboration of several frames, which lead to the construction of a three-dimensional model of the object (therefore opening the possibility of extrapolating three-dimensional measurements) (De Luca 2011).

For the activity we use the Autodesk ${ }^{\circledR}$ Recap Photo ${ }^{\mathrm{TM}}$ (EDU release). This software is limited in the quantity of usable photos (100) the user cannot set the operating parameters (camera calibration, relative and absolute orientations of the frames, etc.). However, since it is a cloud-based software, this allows all students to proceed with the creation of an exportable mesh models without having a powerful pc. Since it is not possible to set control points on individual frames, it is clear how the use of this solution must be calibrated according to the obtainable results (of which is not possible an accurate control) and must be proposed as the first non-definitive approach to the problem of SfM range imaging survey. A consequence of the lack of control is the not always perfect orientation of the elaborated model in the space (Figure 2i), which could therefore be difficult to manage. The workflow involves taking photos with an overlap of about $70 \%$, and at different angles, so that the software can automatically 
recognize a suitable number of homologous points and elaborate the digital model. The use of Recap Photo $^{\mathrm{TM}}$ puts students in front of the possibility of learning a method of taking photos and of a posteriori empirical critical evaluation of the results obtained in a completely automatic way. If the mesh model appears to be consistent with the detected object then we can extrapolate high resolution flat views, obtaining photo planes similar to those processed by RDF. We propose the use of this technique to elaborate detailed drawings (in 1:50 or 1:20 scale) of details of the buildings to be detected and, potentially, to obtain metric information of portions that cannot be directly surveyed (difficult to access or shape) (Figure 2k, 1).

\section{Conclusions (MP-UZ)}

The described educational path must be commented taking into account the context of application of the various tools proposed and the beneficiaries. All the activity, founded on the basis of a learning by doing approach, is aimed at developing the ability to critically select tools and procedures useful for the assigned task. In this sense, the generic redrawing of existing buildings, «carried out by students starting from graphic sources or from real life», or on the basis of metric processed photos, contributes to the construction of the graphic language (and not only) that students should be able to master as future professionals (Spallone 2017, p. 57). Furthermore, the photo rectification, aimed at the realization of a survey, must be taken into consideration when the analysis of the built environment or the study of an architectural artefact does not require its orientation in space based on points of known coordinates, still not fitting for rigorous error control. On the other hand, the automation of the survey process, by means of a simple SfM technique, offers an advanced instrumental approach, with multiple advantages in terms of visual impact of the graphic production, but colliding with the actual impossibility of controlling the process and, therefore, with the real possibility of obtaining materials of difficult interpretation. In this sense, it is fundamental for students to understand its limits above all. In this regard, Paolo Belardi (1996) notes that the mastery of software promotes a sort of new manual skill, no longer limited by the materiality of the 'graphic sign', however it is clear how much there remains a substantial difficulty which sees students as protagonists: their unaware use of software specifically designed to automatically perform important tasks is in no case immediate, but must be determined by a conscious use of the IT medium. In conclusion, the proposed path wants to be the activator of the students' awareness and related development of a critical, implementable approach to the study of the built architectural fact, whose operational phases, part of the path, are applicable tools only on specific cases.

\section{References}

Bassi Gerbi, B. (1995). Fotogrammetria Monoculare, contributo della Proiettiva al recupero delle dimensioni dell'oggetto. Torino: Celid.

Belardi, P. (1996). Paroledisegni. Raccolta di relazioni, memorie e interventi sul disegno. Perugia: Università degli Studi di Perugia.

De Luca, L. (2011). La fotomodellazione architettonica. Rilievo, modellazione, rappresentazione di edifici a partire da fotografie. Palermo: Dario Flaccovio Editore.

Häming, K., \& Peters, G. (2010). The structure-from-motion reconstruction pipeline - a survey with focus on short image sequences. Kybernetika, 46(5), 926-937.

Ippolito, A. (2016). Representing Architectural Heritage: RAH. In A. Ippolito (Ed.), Handbook of Research on Emerging Technologies for Architectural and Archaeological Heritage (1-30). Hershey (PA): IGI Global.

Nelva, R. (1984). Scheda 11, Casa Maffei. In: Politecnico di Torino. Dipartimento Casa-Città. Beni culturali ambientali nel Comune di Torino, Vol. 1 (364). Torino: SIAT.

Piano, R. \& Cassigoli, R. (2009). La responsabilità dell'architetto. Conversazione con Renzo Cassigoli. Bagno a Ripoli: Passigli.

Spallone, R. (2016). Re-drawing architecture for exploring the design. From research to teaching and vice versa. In: E. Echeverría Valiente, \& E. Castaño Perea (Eds.), El arquitecto, de la tradición al sigloi XXI. Dociencia e investigación en expression gráfica arquitectónica. Tomo II (731-738). Alcalá de Henares (ES): Fundación General de la Universidad de Alcalá.

Spallone, R. (2017). Il disegno fra rilievo e progetto nel corso di Architettura della Scuola di applicazione di Torino. In: Il Gabinetto di Architettura antica e Tecnica degli stili. Mostra fotografica (47-59). Torino: Politecnico di Torino.

Zich, U., Comparetto, E., \& Pavignano, M. (2019). From copy to redraw: experiences to learn how to draw for architecture. In L. Gómez Chova, A. López Martínez, \& I. Candel Torres (Eds.), ICERI 2019 proceedings (4721-4730). Valencia: IATED Academy. 